\title{
La Apelación en el Nuevo Proceso Penal Frente al Derecho Constitucional al Debido Proceso ${ }^{* *}$
}

\footnotetext{
* Magister en Derecho Público por la Facultad de Derecho de la Pontificia Universidad Católica de Chile, Profesor de Derecho Politico y Constitucional en la Universidad Católica de Chile, en la Universidad de Chile, en la Universidad de Los Andes y en la Universidad Alberto Hurtado.
}

\section{Introducción}

Aprovechando la instancia que siempre brinda la Facultad de Derecho de la Universidad de Chile, a través de su Revista de Derecho Público, me parece oportuno revisar el régimen de recursos contemplado en el Nuevo Código Procesal Penal, especialmente en relación con el recurso de apelación, de frente a las exigencias impuestas por la Constitución y los tratados internacionales vigentes en nuestro país, en relación con el respeto y promoción del derecho fundamental al debido proceso.

Para realizar la revisión propuesta, resumo, en primer lugar, el régimen de recursos dispuestos por el Código Procesal Penal; en seguida, transcribo las razones de historia fidedigna y doctrina que lo avalan, para luego someterlo al escrutinio constitucional, especialmente, en torno de la decisión legislativa en orden a limitar, severamente, la revisión de los hechos por el Tribunal de Alzada; cierro este artículo, acudiendo al análisis de los preceptos contenidos en la Carta Fundamental, así como de la jurisprudencia nacional e internacional pronunciada en la materia.

\section{Régimen de recursos en el nuevo código}

Útil es comenzar recordando, aunque sea sinópticamente y en lo que aquí interesa, el sistema contenido en el Código Procesal Penal tendiente a impugnar las decisiones judiciales.

Desde esta perspectiva, el artículo $364^{\circ}$ de dicho Código dispone que son inapelables las resoluciones dictadas por un tribunal de juicio oral en lo penal. Por ello, la manera de atacar aquellas decisiones, de acuerdo a su artículo $362^{\circ}$, es a través del recurso de reposición que se deduce, fundadamente y dentro de tercero día, ante el mismo tribunal que las pronunció.

** Este trabajo forma parte del Proyecto Fondecyt N ${ }^{\circ} 1040637$, "La Nueva Justicia Penal frente a la Constitución". 
Por su parte y tratándose de las resoluciones adoptadas por el juez de garantia, sólo son apelables, conforme al articulo $370^{\circ}$, las que pongan término al procedimiento, hagan imposible su prosecución o lo suspendan por más de treinta días y, también, cada vez que la ley señale, expresamente, la procedencia de aquel recurso.

A su turno, el artículo $372^{\circ}$ inciso $1^{\circ}$ expresa que el recurso de nulidad se concede para invalidar el juicio oral y la sentencia definitiva, o solamente ésta, por las causales expresamente señaladas en la ley, las cuales se encuentran contenidas en los artículos $373^{\circ} \mathrm{y}$ $374^{\circ}$ del Código, correspondiendo el conocimiento de las dos primeras de ellas a la Corte Suprema y las restantes a la Corte de Apelaciones respectiva:

1. Cuando, en la tramitación del juicio o en el pronunciamiento de la sentencia, se infringieron sustancialmente derechos o garantías asegurados por la Constitución o por los tratados internacionales ratificados por Chile que se encuentren vigentes;

2. Cuando, en el pronunciamiento de la sentencia, se hizo una errónea aplicación del derecho, lo cual debe haber influido sustancialmente en lo dispositivo del fallo;

3. Cuando la sentencia fue pronunciada por un tribunal incompetente, o no integrado por los jueces designados por la ley; cuando se dictó por un juez de garantía o con la concurrencia de un juez de tribunal de juicio oral en lo penal legalmente implicado, o cuya recusación haya estado pendiente o haya sido declarada por tribunal competente; y cuando la sentencia fue acordada por un menor número de votos o pronunciada por menor número de jueces que el requerido por la ley, o con concurrencia de jueces que no asistieron al juicio;

4. Cuando la audiencia del juicio oral tuvo lugar en ausencia de alguna de las personas cuya presencia continuada exigen, bajo sanción de nulidad, los artículos $284^{\circ}$ y $286^{\circ}$;

5. Cuando al defensor se le impidió ejercer las facultades que la ley le otorga;

6. Cuando en el juicio oral se violaron las disposiciones establecidas por la ley sobre publicidad y continuidad del juicio;

7. Cuando, en la sentencia, se omitió alguno de los requisitos previstos en el artículo $342^{\circ}$, letras $\left.c\right), d$ ) o e);

8. Cuando la sentencia se dictó con infracción de lo prescrito en el articulo $341^{\circ}$; $\mathrm{y}$

9. Cuando la sentencia se pronunció dictada en oposición a otra sentencia criminal pasada en autoridad de cosa juzgada. 
De lo expuesto, surge, inmediatamente, que el Nuevo Código aminora, disminuye restringe $o$, derechamente, prohíbe la revisión completa de la causa, en los hechos y en el Derecho, por un tribunal superior, privilegiando o comprimiendo la competencia de Alzada al examen del Derecho y su aplicación.

\section{Doctrina favorable}

En apoyo del modelo adoptado por el Nuevo Sistema de Enjuiciamiento Penal, conviene acudir a la historia oficial que lo produjo y a la doctrina que lo ha fundamentado. Una y otra merecen ser transcritas con latitud.

\section{Historia Oficial}

Los anales fidedignos del Código Procesal Penal dan cuenta que el tema en examen fue controvertido, pero que se aceptó, en definitiva, el modelo antes resumido:

"En la Cámara de Diputados se consultó qué pasaría si el proceso oral se aprobare y este recurso de apelación fuere equivalente a lo que existe actualmente.

Se contestó que no habría juicio oral. La oralidad del procedimiento requiere que el tribunal que conoce el juicio tenga el máximo poder de decisión. Si en vez de darle el poder de decisión final al tribunal que asiste al juicio oral se le otorga a otro tribunal, que conocerá de la causa por la vía de la lectura del expediente, se estaría poniendo el centro del debate en la lectura del expediente y no en el juicio oral. No sólo se pondría el énfasis en la lectura del expediente sino que se terminaría privilegiando la opinión del tribunal menos informado por sobre la opinión del tribunal más informado.

El recurso de apelación, en el sentido de un tribunal de segunda instancia que conoce con la misma amplitud de competencia y con la misma capacidad de modificación de la sentencia de los tribunales de primera instancia es un recurso propio del sistema inquisitivo y es completamente incompatible con el juicio oral.

Se descartó, por su elevado costo, que la apelación ante el tribunal de alzada diera lugar a una segunda audiencia del juicio oral, similar a la anterior.

Siendo el tribunal del juicio oral colegiado, no se justificaba, en principio, un recurso de apelación como el que ahora existe, que pretende la revisión de la resolución adoptada, tanto en los aspectos de hecho como en los de derecho. 
Esto no significa la indefensión de las partes, desde el momento en que las diferentes hipótesis de error que puedan presentarse están cubiertas por otro recurso.

El Senado estimó conveniente escuchar opiniones acerca del cambio sustancial que tiene el recurso de apelación en el nuevo Código, especialmente la inapelabilidad de las sentencias dictadas por tribunales colegiados.

El profesor Hugo Pereira Anabalón señaló que esta reforma procesal penal se percibe como un instrumento fundamental para la existencia de un sistema judicial moderno y eficaz. Pero la implantación de la única instancia en el proceso oral, agregó, no se condice con las modernas orientaciones doctrinarias y de derecho comparado hoy vigentes, como se infiere de la interpretación finalista y armónica de diversos artículos de tratados y convenios internacionales sobre derechos humanos y que reconocen el derecho de toda persona de recurrir mediante el recurso de apelación en contra de la sentencia agraviante dictada en un proceso especialmente penal, en que es parte.

Los profesores Riego y Tavolari señalaron que hay dos tesis básicas que subyacen en este proyecto. La primera que es contraria a la idea de un juicio oral, concibe a la apelación como un recurso amplio, jerárquico, en que el tribunal superior tiene amplitud de conocimiento sobre todo en los aspectos del proceso de primera instancia.

Y en segundo lugar que la apelación asi concebida no está exigida en los pactos internacionales o en las garantías del debido proceso por la Constitución.

Lo primero, agregaron, parece claro, cuando los proyectistas del Código Modelo mencionan que la apelación supone una repetición de juicio, y si se oponen a eso, es porque asumen una apelación con respeto del principio de la oralidad, o sea, si lo que se quiere es que el tribunal que falle conozca la prueba directamente, la única alternativa es tener un segundo tribunal que conozca de los hechos directamente. La otra alternativa, concebir la apelación como medio de control, significa que el segundo tribunal, el que falla, el que realmente va a tomar la decisión, lo hace a través de la lectura de las actas y eso es por mediación, lo que es propio del sistema inquisitivo, el cual es un sistema registral.

No tiene sentido tener un tribunal colegiado en primera instancia, si todo el mundo sabe que el que verdaderamente va a resolver es alguien que va a leer lo registrado.

Respecto a lo segundo, señalaron que los tribunales internacionales han declarado que no se puede suprimir el derecho a un recurso, no se puede dictar 
un fallo en primera instancia sin que haya posibilidad de reclamar, pero esto no quiere decir que sea el recurso de apelación...

Lo que se debe determinar es saber si bajo el ordenamiento juridico chileno resulta legitima la posibilidad de eliminar la apelación. Si se llegare a la conclusión de que constitucionalmente no es posible el debate está concluido. Expresaron que en América Latina en general, las opiniones tienden a afirmar que el recurso de apelación no está exigido por los Pactos. Pues cuando éstos reconocen al imputado el derecho a recurrir al tribunal superior, puede haber dos interpretaciones, una literal o una más amplia. La mayoría parece inclinarse por una interpretación literal, como lo ha reconocido la Corte Suprema Federal Argentina, que ba dicho que la casación suple sin duda la apelación.

Citando al profesor José Bernales, expresaron que ésta, cuando se refiere al debido proceso, entre cuyo presupuesto incluye la existencia de recursos al tribunal superior, no considera la existencia de tribunales colegiados en primera instancia.

El número de instancias no compromete el derecho de defensa, o al revés, el derecho de defensa no depende del número de instancias que se establezcan, pero lo que es perfectamente posible sustituir la apelación por la casación.

El H. Senador señor Diez señaló que es necesario asumir como presupuesto que la apelación es incompatible con el juicio oral. No se justifica tener un tribunal colegiado en primera instancia para luego duplicar el juicio en la Corte o fallar en base a actas, perdiendo la inmediación necesaria que debe tener el tribunal.

El juicio penal oral y público con un tribunal colegiado es la esencia del debido proceso y es la justificación del ministerio público como órgano acusador independiente; permitir luego que todo sea revisado en base a actas sería borrar de una plumada todo el esfuerzo que ha significado la reforma.

Se agregó que no se concilian ambos sistemas, especialmente porque se suprime la prueba tasada. Además que estableciendo una casación amplia se suple la ausencia de apelación.

El señor Presidente de la Corte Suprema coincidió en que los Pactos internacionales no se refieren a la apelación; a su juicio, lo importante es la posibilidad de revisión de la sentencia por un tribunal superior, por cualquier medio. Agregó que la naturaleza del juicio oral hace inapropiada la revisión en una apelación.

El H. Senador señor Viera-Gallo, señaló que la Cámara compartió estos criterios, pero que manifestó su preocupación por aquellos casos en que la 
apreciación de la prueba es manifiestamente arbitraria y que excede la convicción de la sana crítica y para estos casos se creó el recurso extraordinario, pero que no ve obstáculo en suprimirlo si esta posibilidad se incorporara como una causal de casación.

Este artículo fue motivo de especial estudio, por cuanto, como ya se dijo, de acuerdo a una tesis sostenida ante el Senado, tal precepto podría ser inconstitucional, por vulnerar la obligación de un racional y justo procedimiento que contempla la Carta Fundamental, y por infringir el derecho a revisión de la sentencia penal condenatoria que contemplan el Pacto de San José de Costa Rica y el Pacto Internacional de Derechos Civiles y Políticos.

El Senado no compartió ese punto de vista, ya que ni de la Constitución Politica ni de los citados tratados internacionales se desprende la obligatoriedad para el legislador de establecer el recurso de apelación en materia penal. Aun más, tanto de los antecedentes que tuvo a la vista la Comisión de Estudio de la Nueva Constitución (especialmente el intercambio de ideas habido con el profesor José Bernales, quien planteó la conveniencia de incorporar en alguna forma el concepto anglosajón del debido proceso), como de la jurisprudencia sentada por la Comisión Interamericana de Derechos Humanos, se concluye que el racional y justo procedimiento para la primera y el derecho a revisión del fallo condenatorio para la segunda se alcanzan suficientemente con la existencia de un recurso de casación, que ofrezca la posibilidad de anular la sentencia cuando se hayan vulnerado las garantías procesales.

Despejado este punto, el Senado coincidió con el mérito de la propuesta, en orden a que no sea apelable la sentencia pronunciada por el tribunal de juicio oral. Consideró no sólo la composición del tribunal oral, sino el hecho de que éste habrá desarrollado su trabajo con sujeción a los principios de oralidad y de inmediación, ya que aceptar la apelación importaría destruirlos, porque la Corte de Apelaciones, al conocer de ella, lo haría sobre la base de la escrituración, puesto que deberá estudiar los registros y actas de lo obrado, y de la mediación, toda vez que no tomará conocimiento directo y personal de la prueba. De esta manera, la reforma procesal penal sería sólo aparente, puesto que, por la vía de recurrir de apelación, la última decisión correspondería a un tribunal que seguiría resolviendo del mismo modo en que lo bace boy dia.

Con todo, resolvió hacer mención expresa del tribunal del juicio oral en lo penal, por estimarse que al hablar de tribunal colegiado se puede inducir a error, por ser también tribunales colegiados la Corte de Apelaciones y la Corte Suprema"!

Emilio Pfeffer Urquiaga: Código Procesal Penal Anotado y Concordado (Santiago, Ed. Jurídica de Chile, 2001), pp. $361-364$. 


\section{Doctrina}

La explicación de la modalidad de recursos descrita, donde la apelación deja de ser el recurso por excelencia y es reemplazado por el de nulidad, se ha expuesto en los términos siguientes:

"El sistema de recursos consagrado en el Nuevo Código Procesal Penal se hace cargo de los principios que sustentan al juicio mismo, como son los de oralidad (artículos $266^{\circ}$ y $291^{\circ}$ ) y de inmediación (artículos $266^{\circ}$ y $\left.296^{\circ}\right) \ldots$

Esto que parece obvio, no lo es tanto cuando se estudia la génesis del nuevo Código.

En efecto, el proyecto original consideraba prácticamente el mismo sistema de recursos que se abandona, al punto que, siguiendo a Enrique Tapia Witting '...la mayoría de las resoluciones judiciales, eran impugnables por los recursos legales... '. Esto sin duda no era coherente con el principio de oralidad en virtud del cual una sentencia ' ...sólo puede fundarse en el material proferido oralmente, es decir, cuando los actos procesales se efectúan de viva voz...'. Tampoco lo era con el principio de inmediación, según el cual ha de existir un '...contacto directo de los jueces con la prueba que se rinde en el proceso y con los intervinientes en éste'...

Sobre esta base, es posible sostener, que una de las principales caracteristicas del nuevo sistema es la reducción del número de recursos deducibles, toda vez que se elimina la casación en la forma y la casación en el fondo y aunque no son propiamente medios de impugnación de parte, la consulta y algunas prerrogativas del tribunal ad quem en orden a revisar y reformar las actuaciones del tribunal a quo.

Asimismo, se reducen el número de resoluciones que pueden ser recurridas, como por ejemplo al disponer la nueva ley, que serán siempre inapelables las resoluciones dictadas por un Tribunal Colegiado o que no procede recurso alguno en contra de las resoluciones que recaen en incidentes promovidos en el transcurso de la audiencia del juicio oral.

En efecto, si bien la apelación se mantiene con relativa fuerza en el Nuevo Código Procesal Penal, lo cierto es que ésta '...en cuanto recurso que se puede interponer sin explicitar el gravamen que se imputa a la resolución..., deja de constituir el medio de impugnación que procede por regla general contra toda clase de decisiones'.

Gabriel Nicolás Díaz Campos: "Los Recursos en el Nievo Proceso Penal", en La Semana Jurídica (4 al I0 de marzo de 2002), pp. $5-6$. 
En consecuencia, '...como los elementos probatorios han sido suministrados oralmente, su exacta reproducción en una nueva instancia es imposible, y por lo mismo resulta imposible corregir posibles errores en que se haya incurrido en la instancia y como esta posibilidad de corrección es de la esencia de la apelación, ella no puede darse y por ende tampoco el recurso'.

Así las cosas, la apelación, el recurso que por excelencia hace efectiva la doble instancia, ya no procede en contra de la sentencia definitiva penal, lo que es de toda lógica si pensamos que por regla general, ésta será además dictada por un tribunal colegiado, como es el Tribunal Oral Penal, lo que reduce el riesgo de errores en la apreciación de la prueba que se rinda ante él y en la dictación misma del fallo"2.

Al mismo tiempo que se dan los argumentos aludidos, vinculados con la naturaleza y cercanía del Tribunal, no procede tampoco eludir la situación de las Cortes de Apelaciones en la actualidad, la cual induce a disminuirles su carga de trabajo:

"Las tradicionales competencias que son normales en toda Corte de Apelaciones son los recursos de apelación tanto en materia Civil, criminal, laboral, de policía local, de menores, etc. Estas constituían el grueso de las competencias de las Cortes junto con las consultas de ciertas resoluciones de importancia dictadas en materia penal, en caso de no ser apeladas.

Este panorama se ha visto violentamente alterado por el surgimiento de nuevas competencias que tanto en primera como en segunda instancia han provocado un aumento sustancial en el trabajo judicial de las Cortes, más allá de la natural expansión de las necesidades de justicia por la evolución económica y social" 3 .

En fin y profundizando más en torno de estas ideas, conviene tener presente, en nexo preciso con el respeto del debido proceso, que:

"...la desaparición de la doble instancia como mecanismo de control de la sentencia definitiva merece, por su importancia, una consideración especial.

En efecto, como limitación al ámbito de aplicación de los recursos, la inadmisibilidad del recurso de apelación en contra de las resoluciones que se pronuncian sobre incidentes promovidos durante la audiencia del juicio oral fue absolutamente pacifica durante la tramitación del proyecto de ley...

Completamente distinta fue, sin embargo, la decisión de declarar inadmisible el recurso de apelación en contra de las sentencias definitivas dictadas 
en el procedimiento ordinario. La existencia de una larga tradición en nuestro país, que asignaba al recurso de apelación contra la sentencia definitiva el carácter de una garantía para el imputado, se hizo presente durante el debate legislativo, defendiendo la subsistencia del recurso de apelación en el nuevo sistema.

En efecto, la supresión del recurso de apelación como método de control de la sentencia definitiva dictada tras un juicio oral fue, en primer lugar, justificada en el Mensaje del Proyecto del Ejecutivo como una necesidad impuesta por los principios de oralidad e inmediación...

La contradicción existente entre el recurso de apelación y los principios de inmediación y oralidad fue expuesta, luego, con gran vigor, durante la tramitación legislativa del proyecto...

El problema a resolver, entonces era de orden constitucional. La supresión del recurso de apelación abría una discusión en torno a la mejor manera de defender los principios constitucionales del debido proceso y de garantizar el derecho de defensa. Porque ésos son los valores que consideran comprometidos quienes se oponen a la supresión del recurso de apelación. Como expone Ferrajoli: 'El doble examen del caso bajo juicio es el valor garantizado por la doble instancia de la jurisdicción, doble instancia que es, al mismo tiempo, una garantía de la legalidad y de responsabilidad contra la arbitrariedad...'.

A nuestro juicio, la decisión legislativa de suprimir en Chile el recurso de apelación en contra de las sentencias definitivas dictadas en juicio oral está lejos de sacrificar ninguna garantía fundamental. Habiéndose concebido en primera instancia un tribunal colegiado integrado por tres miembros, cuyas decisiones son impugnables a través del recurso de nulidad, y habiéndose estructurado este último como un recurso desformalizado, que permite controlar, según veremos, el respeto a los derechos y garantías comprometidos en el procedimiento penal y la conformidad de la sentencia con las reglas de la sana crítica, la posibilidad de apelación habría resultado del todo superflua. Lo que resulta realmente trascendente desde el punto de vista del derecho al recurso no es la doble instancia, sino la doble conformidad...

... La doble conformidad supone, entonces, que la condena debe ser capaz de subsistir el reexamen en un nuevo juicio, si se cumplen los requisitos que habilitan la revisión"

Marfa Inés Horvitz Lennon y Jujián López Masle: II Derecho Procesal Chileno (Santiago, Ed. Juridica de Chile, 2004), pp. 354 - 360. En el mismo sentido, aunque sólo constatando los antecedentes históricos, J. Cristóbal Núnez Vásquez: II Tratado del Proceso pena y del Juicio Oral (Santiago, Ed. Jurídica de Chile, 2003), 289 290. 
Llevado el asunto a un análisis de los procedimientos, en general, y contrastando lo civil y lo penal, sin embargo, se argumenta, por la doctrina comparada, a favor de un sistema como el que hoy se contempla en el Código Procesal Penal. Y una vez más hago una transcripción extensa, favoreciendo las argumentaciones que contribuirían a disipar las dudas de constitucionalidad que se expresarán en seguida:

"Si el sistema de recursos se incorpora a la tutela judicial con la configuración que le otorga cada una de las leyes reguladoras de los diversos órdenes jurisdiccionales, sin que exista un derecho constitucional a disponer de tales medios de impugnación, es real la eventualidad de que no existan, salvo, como veremos, en el ámbito penal. No puede encontrarse en la Constitución ninguna norma o principio que impongan la necesidad de una doble instancia o de unos determinados recursos, siendo posible en abstracto su inexistencia o condicionar su admisibilidad al cumplimiento de determinados requisitos. El establecimiento y regulación en esta materia pertenece al ámbito de libertad del legislador $y$, como consecuencia, el principio hermenéutico pro actione no opera con igual intensidad en la fase inicial del proceso, para acceder al sistema judicial, que en las sucesivas... En definitiva, la diferencia entre el acceso a la jurisdicción y el acceso a los recursos se proyecta necesariamente en la función de control que corresponde al Tribunal Constitucional respecto de las resoluciones judiciales que impidan de una u otra forma el derecho fundamental a la tutela judicial efectiva...

Pero esta doctrina sobre el origen meramente legal del derecho a los recursos tiene como excepción el ámbito penal, en que son también abundantes las sentencias que, invocando el artículo 14.5 del Pacto Internacional de Derechos Civiles y Políticos, reconocen el derecho a la previsión legal del recurso en los términos que en dicho artículo se establecen: 'Toda persona declarada culpable de un delito, tendrá derecho a que el fallo condenatorio y la pena que se le haya impuesto sean sometidos a Tribunal Superior, conforme a lo prescrito por la ley'...

Ahora bien esta vinculación que impone el Pacto Internacional mencionado no siempre ha sido entendida de una manera uniforme. Frente a quienes sostienen que supone la necesidad de generalizar en nuestro ordenamiento el recurso de apelación contra la sentencia penal, el Tribunal Constitucional, que en algunas sentencias ha 'recomendado' el establecimiento de la segunda instancia e incluso ha excepcionado en -declaraciones ob interdicta-el ámbito penal de la doctrina por él establecida en el sentido de que el derecho fundamental a los recursos no incluye la segunda instancia, ha sostenido que el artículo citado del Pacto Internacional sólo obliga a la sumisión del fallo condenatorio a un Tribunal Superior: 'De la lectura del artículo 14.5 del Pacto se desprende claramente que no establece propiamente una doble instancia, sino un sometimiento del fallo y de la condena a un Tribunal Superior, y como estos requisitos se dan en nuestra casación, este Tribunal ha entendido que tal recurso, a pesar de su cognición res- 
tringida, cumple la función revisora y garantizadora exigida por el artículo 14.5 del Pacto'... Por eso, sin duda, el Tribunal Constitucional, a pesar de las demandas dirigidas desde distintos ámbitos doctrinales, no ba declarado inconstitucional el sistema de única instancia imperante en el proceso penal ordinario por delitos graves.

Esta doctrina, por lo demás, es conforme no sólo con la literalidad del articulo 14.5, sino con su interpretación lógica, por lo menos por estas razones: 1) $E l$ Pacto tomó como inspiración básicamente la legislación norteamericana en la que se parte de una sentencia dictada por un Tribunal del Jurado y el derecho al recurso es sólo una garantía del condenado - no del Ministerio Fiscal- que tiene por contenido la revisión de si se ha respetado el derecho al proceso debido y si la pena se ha fijado aplicando una ley inconstitucional, pero nunca la revisión de la valorización de la prueba; 2) el precepto en cuestión sólo reconoce el derecho a 'la persona declarada culpable de un delito', no a las partes acusadoras, por lo que la garantía opera exclusivamente en caso de sentencia condenatoria $\mathrm{y}$ a favor del condenado que será el único legitimado para recurrrir, lo que no calza bien con la imposición de la exigencia de un recurso de apelación que abra una segunda instancia en sentido técnico; 3 ) no se puede pretender que el Pacto haya tratado de conformar un sistema unitario de recursos en el ámbito penal para todos los países firmantes del mismo, sino de establecer una garantía mínima asumible por ellos.

Resulta obvio que estas garantías las cumple nuestro recurso de casación. En consecuencia, no se puede sostener en nuestro ordenamiento la existencia de un derecho constitucional a la segunda instancia en el orden penal, sino sólo del derecho a que el fallo condenatorio y la pena sean revisados por un Tribunal superior, que es algo diferente y que en el momento actual encuentra plena satisfacción con el recurso de casación...

Por lo demás, una segunda instancia en la que no están limitados los poderes del Tribunal de Apelación en la revisión del juicio de hecho y de derecho llevado a cabo por el Juez de la primera parece más propio de un proceso como el civil en el que dominan las pruebas documentales y el principio de inmediación en su práctica tiene un alcance más limitado que el penal. En este ámbito, en el que la inmediación juega de una manera más estricta, la posibilidad de que el Tribunal de Apelación revise la valoración de la prueba realizada en primera instancia supone una excepción importante de dicho principio: El Tribunal no juzga con base en las pruebas practicadas ante él (salvo los casos excepcionales en que es admisible la prueba en segunda instancia), sino por las que se practican ante el juzgado. Además, puede ocurrir que, al prevalecer en el proceso penal la prueba testifical sobre la documental, el acta del juicio oral no recoja fielmente los resultados de esta prueba testifical o de cualquier otra de tipo personal. Ante la no imposición de la 
utilización preceptiva de los medio de grabación y reproducción que ofrece la técnica moderna, puede ocurrir que el juez de apelación se encuentre en inferioridad a la hora de valorar la prueba, por no tener a su disposición los resultados probatorios tal y como se produjeron.

En definitiva, parece que un sistema de doble instancia en sentido estricto sólo es posible en la medida en que exista reflejo documental exacto de lo practicado en la primera, y esto sólo queda garantizado en el proceso civil, que es un proceso escrito en el que tiene carácter predominante la prueba documental. En el proceso penal, la vigencia del principio de oralidad, el mayor rigor exigible al de inmediación y el predominio de las pruebas de tipo personal, convierten la segunda instancia en arriesgada, porque no es posible sustituir la valorización de la prueba realizada por el Juez de primera instancia practicada conforme a aquellos principios de oralidad, inmediación y publicidad..." .

En otra perspectiva, no tan latamente transcrita como la anterior, que puede contribuir al tema, recojo algunas ideas provenientes del análisis económico del Derecho:

"Muchos sistemas judiciales consisten en una jerarquía de tribunales donde un litigante inconforme puede apelar la decisión de un tribunal inferior y pedir un nuevo juicio en un tribunal superior. $A$ veces, el tribunal superior debe aceptar la apelación y conocer el caso, y a veces el tribunal superior puede escoger entre aceptar la apelación o rechazarla... A veces, el tribunal de apelación puede conocer todo el caso desde el principio... A veces, sin embargo, el tribunal de apelación considera algunas cuestiones pero no otras. Por ejemplo, los tribunales de apelación de los países del derecho común suelen limitar su consideración a las cuestiones de derecho, aceptando sin revisión todos los hechos descubiertos por los tribunales inferiores...

Los tribunales de apelación tienen dos funciones distintas. Primero, corrigen los errores cometidos en las decisiones tomadas por los tribunales inferiores. "Segundo, hacen leyes, mediante la interpretación de los estatutos..."

Finalmente, en sentido semejante y profundizando lo expuesto, desde el ángulo del Tribunal de Alzada a objeto de no eludir las argumentaciones que permitirían salvar la constitucionalidad de la decisión legislativa adoptada en nuestro Nuevo Proceso Penal, recuérdese que:

Faustino Cordón Moreno: Las Garantáas Constitucionales del Proceso Penal (Navarra, Ed. Aranzadi, 2002), pp. 203 - 209.

Robert Cooter y Thomas Ulen: Derecho y Economía (México, Fondo de Cultura Económica, 1998), pp. 530 -531. 
“...La apelación sirve a dos propósitos sociales: Reducir los costos del error legal... y permitir la creación y conservación de reglas de derecho uniformes. Dado que comúnmente la parte perdedora no desea mejorar la ley, pareciera que hubiese muy pocas apelaciones... Pero hay un mecanismo equilibrador natural. Si hay muy pocas apelaciones en el período uno, bajará la producción de precedentes de los tribunales de apelación, lo que dificultará que los individuos arreglen sus disputas (porque no se pueden poner de acuerdo sobre cómo tenderán a resolverse las disputas en el tribunal), lo cual conducirá a más litigios y por ende a más apelaciones en el período dos.

Los tribunales de apelación hacen una revisión total de los puntos de derecho... Pero los tribunales de apelación respetan ampliamente los hechos aclarados por el juez de primera instancia o el jurado... el juez de primera instancia incurre en costos de información menores para aclarar los hechos que los jueces de la apelación que no reciben a los testigos.

Los tribunales de apelación no revocan los errores inocuos. Por definición, es poco probable que tales errores conduzcan a un resultado diferente si el caso vuelve a juzgarse. El beneficio esperado de la revocación en tal caso es bajo en relación con el costo de los procedimientos adicionales que tendrían que realizarse en el juzgado de primera instancia si se revocara el fallo.

... El sistema federal, como casi la totalidad de los Estados y la mayoría de los países extranjeros, ha establecido criterios a favor de posponer la revisión hasta el final del procedimiento en el juzgado de primera instancia... Sin embargo, está llena de excepciones...

Se obtienen dos beneficios cuando se permiten las apelaciones inmediatas de los fallos intermedios. El primero es que se evita la demora en determinar la corrección lo que podría evitar procedimientos prolongados. Pero con estos dos beneficios hay dos costos. El primero es que el procedimiento en conjunto podria demorarse por las interrupciones frecuentes. El segundo es que posponer la revisión en apelación podría evitar procedimientos innecesarios de apelación...

Resulta inevitable, que el sistema federal haya otorgado mayor peso a la economía del tiempo de los jueces de apelación que a la de los jueces de instrucción. La razón se encuentra en la estructura piramidal de un sistema judicial combinado con la extensión geográfica del sistema judicial federal "?.

Richard A. Posner: El Análisis Económico del Derecho (México, Fondo de Cultura Económica, 1998), pp. 549 -550 . 


\section{Examen Constitucional}

Habiendo señalado, sinópticamente, el régimen de los recursos principales en el Código Procesal Penal, y habiendo transcrito, sin formular juicios de valor u opiniones, la historia oficial y doctrina que apoya y fundamenta aquel régimen, procede ahora someterlo al escrutinio constitucional y de los tratados internacionales.

\section{Planteamiento}

Desde luego, debe reconocerse que el régimen de recursos expuesto, no obstante las argumentaciones vertidas, provoca dudas de constitucionalidad, ya que se trata de una normativa que limita severamente la procedencia del recurso de apelación, sobre todo, si es que se llegara a considerar que todo lo actuado -en los hechos y en el Derecho-por un tribunal debe ser susceptible de revisión por otro como regla del respeto al debido proceso:

"Con relación a los requisitos del proceso y por tratarse de elementos diferentes, no es correcto confundir la legalidad positiva oficial, la racionalidad sustantiva en que ha de fundarse aquélla y el imperativo esencial de justicia que debe cumplir tal proceso. En consecuencia, esas tres condiciones tienen que reunirse copulativamente...

... surgieron objeciones a tal predicamento, fundadas en que sería menester no sólo definir los requisitos enunciados..., sino que, además, habría que agregar otros presupuestos reputados igualmente esenciales... Entre los últimos, tal imperativo cubriría la publicidad de las actuaciones, el derecho a la acción, el emplazamiento, el examen y la objeción de la prueba rendida, la bilateralidad de la audiencia, la facultad como regla general para interponer recursos, el pronunciamiento de los fallos dentro de los plazos previstos en la ley y la fundamentación de las sentencias con arreglo al sistema jurídico en vigor.

... todos y cada uno de los elementos mencionados son de la esencia de un proceso racional y justo, pero ellos no agotan las exigencias de la racionalidad y justicia..." $"$.

8 José Luis Cea Egaña: El Sistema Constitucional de Chile. Síntesis Crítica (Valdivia, Facultad de Ciencias Jurfdicas y Sociales de la Universidad Austral de Chile, 1999), p. 275 - 276; e Iris Vargas Delgado: "La Garantfa del Justo y Racional Procedimiento en la Jurisdicción Tributaria”, XXV Revista Chilena de Derecho № 3, pp. 549 -552 . 


\section{Contenido de un Procedimiento Racional y Justo}

Formulado el problerna y admitiendo que las argumentaciones vertidas para superarlo no son capaces de disipar las dudas, tiene que elevarse el análisis para situarlo en el máximo nivel de nuestro ordenamiento jurídico interno y en las obligaciones internacionales que nuestro país ha asumido en la materia, es decir, resulta imperativo avanzar en el sentido y alcance del debido proceso en la Constitución y en los tratados vigentes en Chile.

En esta línea de pensamiento, vuelvo a una idea que he expuesto con anterioridad', en cuanto a que, si bien es cierto, el derecho al debido proceso posee un indudable y muy principal componente formal, también se encuentra integrado -en su esencia, para utilizar la expresión del artículo $19^{\circ} \mathrm{N}^{\circ} 26$ de la Constitución- por elementos sustantivos o materiales de igual o, incluso, en un momento dado o frente a un caso determinado, de mayor relevancia.

“...existen requisitos sustantivos y formales que han de ser cumplidos a fin de que la función jurisdiccional logre ser justa...

El más importante es la imparcialidad del órgano jurisdiccional, vale decir, su obrar sin prejuicio o designio anticipado a favor o en contra de personas, ideas, situaciones, de igualdades, diferencias y de cosas.

Tribunal o juez, imparcial es, en suma, sólo aquel que procede y juzga con rectitud. Imparcial es, por lo mismo, el órgano jurisdiccional impersonal o institucionalmente concebido, cuyo actuar es objetivo, dirigido sólo por la justicia y que, para realizarla, vence o rechaza cualquier circunstancia extraña a su oficio.

Presupuesto de una exigencia tan difícil como necesaria es gozar de independencia, servir rectamente la jurisdicción, estar sujeto a controles y asumir las responsabilidades derivadas de conductas ilícitas. Se examinarán brevemente estas cuatro condiciones de la imparcialidad descrita.

a) Independencia. Ella es, principalmente, la cualidad que los órganos jurisdiccionales adquieren cuando se dedican, en realidad, a impartir justicia prescindiendo de conductas impropias, derivadas de la subordinación y dependencia; sobreponiéndose a presiones e influencias; apartando su mente de los halagos o rechazando favores e insinuaciones que alteren la libre e igual interpretación y aplicación del Derecho a los asuntos de su competencia; y demostrando la vivencia de aquellos valores cualesquiera sean los favorecidos o afectados con sus sentencias.

Profundícese en Miguel Ángel Fernández González: "Derecho a la Jurisdieción y Debido Proceso", en Estudios Constitucionales (Santiago, Editorial Universidad de Talca, Año $2 \mathrm{~N}^{\circ}$ 1, 2004), pp. 99 - 121. 
La independencia de un Tribunal es, en resumen, la ausencia de toda influencia...

La función jurisdiccional, en efecto, exige desenvolverse en un proceso racional y justo, legalmente tramitado con anterioridad a la sentencia que lo decide...

El debido proceso, legal y justo, presupone, entre otros elementos, los siguientes:

Un órgano imparcial e independiente;

Que sea competente en el asunto o materia sometida a su resolución;

En que las partes tengan igualdad de oportunidades para acceder a los órganos jurisdiccionales, entablar acciones, rendir pruebas y defenderse;

Sin que ninguna de ellas quede en situación de ignorar lo obrado por la contraria;

Contemplándose recursos para que los tribunales superiores revisen lo decidido por los inferiores, salvo situaciones excepcionalísimas en que sea legítima la única instancia;

En que el procedimiento entero, salvo limitadísimas excepciones previstas por la ley en texto expreso y de interpretación estricta, se desenvuelva con publicidad, o sea, con la transparencia o visibilidad pública de sus diversas etapas.

Pero esos son tan sólo algunos de los presupuestos mínimos o esenciales de un proceso justo. Siempre será necesario, en consecuencia, ir perfeccionándolo para que sea lo más legítimo posible. Trátase, en suma, de un ideal a la consecución del cual el Poder Constituyente llama, con carácter constante e incesante, al legislador en la disposición fundamental ya citada"10.

Precisamente, evaluando la concurrencia de aquellas condiciones sustantivas o materiales, respecto de un órgano jurisdiccional que no integra el Poder Judicial, la Corte Suprema ha resuelto:

"La Constitución establece ciertos principios que se deben observar por el Estado al ejercer su potestad tributaria, tanto al imponer tributos, como al fiscalizarlos y resolver los conflictos que puedan presentarse. Entre ellos... el debido proceso, concepto que corresponde a los tribunales ir enriqueciendo a través de la jurisprudencia y que 'comprenderá no sólo aquellos elementos que 
emanan de la propia naturaleza del hombre, que son los mínimos y que, en definitiva, consisten en ser oído, en poder recurrir, en la mayoría de las veces a otro tribunal' (Comisión de Estudio de la Nueva Constitución, sesión 108, de enero de 1975), elementos entre los cuales ciertamente se incorpora aquel que exige el establecimiento de los tribunales en forma permanente por el legislador y con anterioridad a la iniciación del juicio, el que deberá ser seguido ante un juez imparcial, dentro de un procedimiento contradictorio, bilateral y con igualdad de derechos para las partes, que permita exponer adecuadamente las pretensiones, defensas y oposiciones, en su caso, haciendo posible el ofrecimiento, aceptación y recepción de los medios de prueba en que aquellas se funda, obteniendo una decisión por un juzgador imparcial e independiente.

La legalidad de la función jurisdiccional se plasma en diversas normas de nuestro Código Político, al señalar que nadie puede ser juzgado por comisiones especiales, sino por el tribunal que señale la ley que se halle establecido con anterioridad por ésta (artículo $19 \mathrm{~N}^{\circ} 3$ inciso $4^{\circ}$ ); imponiendo la limitación de que toda sentencia de un órgano que ejerza jurisdicción, no únicamente los tribunales, debe fundarse en un proceso previo legalmente tramitado, correspondiendo al legislador establecer siempre las garantías de un procedimiento y una investigación racionales y justas (artículo 38 inciso $2^{\circ}$ )... por todo lo cual la unanimidad de la doctrina nacional opina que, exclusivamente, corresponde a la ley, como fuente de Derecho, establecer los tribunales, y a la función legislativa, ejercida privativamente por el Congreso, acordar sus disposiciones, de modo que "la única autoridad que puede crear tribunales con carácter permanente, es la ley. Ningún tipo de normas de Derecho, de jerarquía inferior (reglamentos, decretos, etc.) puede dar origen a tribunales' (Alejandro Silva Bascuñán. Tratado de Derecho Constitucional, tomo Il, página 21).

A lo anterior se agrega que 'todo juzgamiento debe emanar de un órgano objetivamente independiente y subjetivamente imparcial, elementos esenciales del debido proceso, del cual son aspectos consustanciales', según ha tenido oportunidad de expresarlo el Tribunal Constitucional en su sentencia de 21 de diciembre de 1987, considerando $10^{\prime \prime 1}$.

De lo expuesto surge nítido que el respeto del debido proceso no constituye sólo una cuestión de secuencia adecuada en etapas sucesivas, sino que, especialmente, consideran-

Considerandos $4^{\circ}$ y $5^{\circ}$ de la sentencia pronunciada por la Corte de Apelaciones de Santiago el 29 de marzo de 2001 -confirmada por la Corte Suprema el 7 de junio de 2001-, publicadas en Gaceta Jurídica No 252 (2001) pp. 206 ss., reproducidos por José Luis Cea Egaña: 11 Derecho Constitucional Chileno (Santiago, Ediciones Universidad Católica de Chile, 2004), pp. $162-163$. 
do su naturaleza de derecho fundamental, o sea, garantizado por la Constitución y los tratados ratificados y vigentes en Chile, posee una materialidad que no puede ignorarse:

“...'Law' no corresponde en su acepción norteamericana original a un sometimiento del concepto 'Process' a una idea más bien formal de ley, sino, y más bien relacionada con apuntes como los ya hechos en este mismo trabajo, se encuentra vinculada a un respeto a las diferentes dimensiones del Debido Proceso (no solamente al seguimiento de ciertas formas, sino principalmente a la plena vigencia de los valores que se encuentran detrás o buscan protegerse con este concepto), y, por qué no decirlo, de la visión del Derecho y lo jurídico que se maneja en Estados Unidos, la cual como todos sabemos no se limita a las prescripciones hechas por algún legislador.

Sin embargo, estos diversos alcances, así como aquellos relacionados a las distintas manifestaciones del derecho al cual venimos aquí abordando (expresiones habitualmente denominadas Debido Proceso Sustantivo o Debido Proceso Procesal, cuyo contenido ya ha sido detalladamente descrito en otros trabajos, no fueron inicialmente recogidos, o siquiera suficientemente conocidos, por los legisladores y juristas de nuestros páses. El Debido Proceso era en un principio un derecho más bien relacionado con el cumplimiento de parámetros fundamentalmente de carácter formal dentro del quehacer jurisdiccional. Ha sido más bien, tal como ya se había señalado, la labor de Tribunales internacionales de protección de Derechos Humanos, así como reiterada jurisprudencia de algunos juzgadores ordinarios y/o constitucionales lo que ha permitido rescatar el sentido original del 'Due Process...' en América Latina, pero ello también, y tema que sin duda es importante resaltar y al cual iremos posteriormente, ha permitido tener presente la existencia-o el surgimiento, dependiendo de nuestra perspectiva 0 acercamiento a estas materias- de otro tipo de eventuales riesgos ${ }^{n 12}$.

Por ello, el respeto al derecho al debido proceso no se agota en el cumplimiento de unas condiciones o requisitos procesales o meramente formales, como cuando se establecen recursos sin importar qué o cómo impugnan ni cuál es la competencia que confieren al Tribunal Superior, sino que requiere el acatamiento estricto de condiciones sustantivas, con lo cual el apego del órgano jurisdiccional al derecho a un procedimiento racional y justo no se entiende cumplido cuando se respeta sólo el procedimiento dispuesto por la ley, si éste adolece de lesiones a ese derecho fundamental, sin que el juez pueda escudarse, para reputar su conducta respetuosa de la Carta Fundamental, en la sujeción estricta a la ley procesal, si con ello no realiza plenamente los derechos que la Carta Fundamental asegura en su artículo $19^{\circ} \mathrm{N}^{\circ} 3^{\circ}$ en relación con lo dispuesto en el artículo $8^{\circ}$ de la Convención Americana.

12 Eloy Espinosa-Saldaña Barrera: "Jurisdicción Constitucional, Debido Proceso y los Márgenes de Acción del Juez Constitucional" en Estudios Constitucionales (Santiago, Centro de Estudios Consticucionales de la Universidad de Talca, Año I No 1, 2003), pp. 360 - 361. 


\section{Impacto en el Nuevo Proceso Penal}

Lo anterior, en el caso de dicho Proceso, adquiere todavía mayor relevancia cuando la reducida procedencia del recurso de apelación puede conducir, como es obvio aventurar, a que sea reemplazado por el de nulidad previsto en los artículos $372^{\circ}$ y siguientes del Código Procesal Penal, con lo cual se puede provocar que se atiborre a la Corte Suprema -como ha ocurrido, en el Sistema Antiguo, con las Cortes de Apelacionesconforme a la causal prevista en el artículo $373^{\circ}$ letra a) del Código; y, tal vez como reacción a lo anterior, el recurso de nulidad va a ir perdiendo valor, haciendo que los procesos penales terminen siendo de única instancia:

"El valor de la regulación legal de la apelación es discutido. Resulta sorprendente a primera vista que justamente en los hechos punibles más graves y significativos, que en primera instancia pertenecen a la competencia de la Gran Cámara Penal, del Tribunal de Jurados o del OLG, le sea negada al acusado una segunda instancia fáctica. Sobre esta regulación legal se han formulado las consideraciones que siguen.

La composición más numerosa de los tribunales superiores posibilita un enjuiciamiento más cuidadoso y, con ello, torna superfluo un segundo juicio oral. También, por regla, con motivo de las investigaciones de la etapa preparatoria, el objeto del proceso resulta ya fundamentalmente aclarado. Esto hace que los procesos por casos cotidianos de criminalidad de mediana gravedad, que caen bajo la competencia del AG, sean necesariamente sumarios.

A pesar de ello, justamente en los delitos de importancia capital, y a causa de que en ellos las consecuencias jurídicas son especialmente graves, se exige una segunda instancia fáctica. En cambio, se le niega todo valor a la apelación en los demás casos, dado que, con el correr del tiempo, las posibilidades de la prueba serían cada vez peores y, con ello, no habría garantía alguna de una mejor justicia a través de segunda instancia de mérito. También se sostiene que los jueces de primera instancia, precisamente a causa de la posibilidad de la apelación, trabajan con menos cuidado, ya que saben que existe una segunda instancia de mérito. A través de la aceptación de la apelación, el momento central del proceso penal es trasladado a la segunda instancia. La necesidad de la instancia de apelación es puesta en duda también debido a que los tribunales de casación, en contra de la concepción legal originaria, examinan cada vez más las comprobaciones fácticas de la primera instancia" ${ }^{13}$.

13 Claus Roxin: Derecho Procesal Penal (Buenos Aires, Ediciones del Puerto, 2000), p. 457. 
De hecho una nota aparecida en La Semana Juridica, donde, a propósito de una sentencia de la Corte Suprema pronunciada el 6 de marzo de 2003 en causa Rol N ${ }^{\circ} 609$ - 2003, en la cual dicho Alto Tribunal rechazó el recurso de nulidad porque no se precisaba la causal en que lo fundaba el recurrente, sino que se limitaba a aludir genéricamente el derecho del debido proceso que la Constitución, las leyes y los tratados le reconocían, llevó al editor de aquel semanario jurídico a expresar, con razón:

"En más de una oportunidad hemos proporcionado antecedentes estadísticos sobre la suerte que corren los recursos de casación de forma y fondo establecidos en el Código de Procedimiento Penal.

Al parecer el recurso de nulidad que prevé el nuevo Código Procesal Penal no tendrá mejor fortuna..."14.

Por eso, la Corte Interamericana de Derechos Humanos ha resuelto, en Juan Humberto Sánchez vs. Honduras, que:

"Esta Corte ha establecido que no basta que los recursos existan formalmente sino que los mismos deben dar resultados o respuestas a las violaciones de derechos humanos, para que éstos puedan ser considerados efectivos. Es decir, que toda persona debe tener acceso a un recurso sencillo y rápido ante jueces o tribunales competentes que amparen sus derechos fundamentales. Dicha garantía 'constituye uno de los pilares básicos, no sólo de la Convención Americana, sino del propio Estado de Derecho en una sociedad democrática en el sentido de la Convención '. Además, como igualmente ha señalado el Tribunal, "[n]o pueden considerarse efectivos aquellos recursos que, por las condiciones generales del pais o incluso por las circunstancias particulares de un caso dado, resulten ilusorios '...

Sobre las garantías judiciales o también conocidas garantías procesales, la Corte ha establecido que para que en un proceso existan verdaderas garantias judiciales, conforme a las disposiciones del artículo $8^{\circ}$ de la Convención, es preciso que se observen todos los requisitos que 'sirv [a] n para proteger, asegurar o hacer valer la titularidad o el ejercicio de un derecho', es decir, Las 'condiciones que deben cumplirse para asegurar la adecuada defensa de aquéllos cuyos derechos $u$ obligaciones están bajo consideración judicial "15.

En efecto, los preceptos fundamentales exigen el respeto de condiciones formales y materiales, mencionando entre estas últimas, desde luego, la racionalidad y justicia del procedimiento; el derecho a ser oído; que el tribunal sea competente, independiente e imparcial; que se encuentre establecido por la ley y con anterioridad a los hechos que va a juzgar; y que cuando se trate de la defensa de derechos fundamentales las personas

La Sernana Juridica, 24 al 30 de marzo de 2003, p. 13.

Motivos 121 y 124 de la sentencia pronunciada el 7 de junio de 2003. 
tengan derecho a un recurso sencillo y rápido que permita revisar cuanto ha sido actuado por el Tribunal de Primera Instancia:

"Podemos provisionalmente concluir que en los Estados Unidos la garantía del juicio limpio no es un concepto simple, sino una combinación de elementos que aseguran una determinada forma de proceso en torno a los valores, equidad, imparcialidad, independencia, igualdad, publicidad, racionalidad, certeza y universalidad, estando todos ellos incluidos y presentes en la cláusula del Due Process of Law que además incorporan otros requisitos específicos contenidos en otras partes de la United States Code"16.

Equidad, imparcialidad, independencia, igualdad, publicidad, racionalidad, certeza y universalidad. He allí los valores sustantivos que integran, junto a las condiciones o requisitos formales, el derecho al debido proceso:

"En otras palabras, no basta para respetar el debido proceso con ceñirse a la ley que dispone un determinado procedimiento, sino que, respetando y aplicando los principios de supremacía constitucional y fuerza normativa de la Carta Fundamental, conforme a su artículo $6^{\circ}$ incisos $1^{\circ}$ y $2^{\circ}$, así como lo dispuesto en los artículos $8^{\circ}$ y $25^{\circ}$ de la Convención Americana tiene siempre que comprenderse y aplicarse el debido proceso, considerando su naturaleza de derecho fundamental...

Por ello, en suma, el órgano jurisdiccional no sólo tiene que ser respetuoso de la legalidad procesal, sino que de los requisitos de racionalidad y justicia, cuyo acatamiento es exigido desde la misma Constitución. De esta manera, el respeto del derecho al debido proceso no consiste sólo en verificar que se acate aquella legalidad procesal, sino que, superlativamente y con independencia de ella, que haya respeto por los elementos sustantivos requeridos en la Carta Fundamental, complementada por la Convención Americana" 17.

Por cuanto viene siendo expuesto, no puede menos que concluirse que la regla de la doble instancia forma parte del derecho al debido proceso, con lo cual la competencia del Tribunal de Alzada tiene que extenderse y comprender tanto la revisión de los hechos $y$ del Derecho cuanto la evaluación acerca de la apreciación que de la prueba haya realizado el Tribunal Inferior.

\section{Jurisprudencia Nacional}

Conforme a lo resuelto por el Tribunal Constitucional, tratándose de un recurso de derecho estricto y más excepcional que el de apelación o el de nulidad en el Nuevo

\footnotetext{
Iñaki Esparza Leibar: El Principio del Debido Proceso (Barcelona, Ed. Bosch, 1995), pp. 7] - 77

Miguel Ángel Fernández González cirado en supra noca 9, pp. 118.
} 
Código, como el de casación, cabe imaginar, con cierta certeza, cuál habría sido su posición si, como debió ocurrir, el Código Procesal Penal hubiera sido sometido a control obligatorio de constitucionalidad, conforme al artículo $82^{\circ} \mathrm{N}^{\circ} 1$ ) de la Carta Fundamental:

"Que, mediante el recurso de casación en el fondo, el sistema procesal da eficacia al principio de legalidad y al de igualdad ante la ley, garantizados ambos plenamente por la Constitución Política, como se verá más adelante, toda vez que se ha establecido un solo tribunal competente para conocerlo con el objeto de que éste resuelva si ha existido error de derecho en la sentencia recurrida y si lo hubiere la anule y restablezca el imperio de la norma violentada.

Con ello se logra que sea la Corte Suprema, cuyas sentencias no son susceptibles de recursos, la que fije la correcta aplicación de la ley decisoria litis.

Se trata de evitar el error judicial y de buscar mecanismos para corregirlo cuando él haya sido cometido por los jueces de la instancia al manifestar su voluntad en la sentencia.

En este entendido, nuestro sistema procesal constitucional contempla los siguientes principios fundamentales que dicen relación con la materia que debe resolverse...:

b.- Debido proceso. La Constitución en el artículo $19, \mathrm{~N}^{\circ} 3$, asegura a todas las personas la igual protección de la ley en el ejercicio de sus derechos. Esto significa que los afectados que estimen que los tribunales de la instancia no han aplicado correctamente la ley que regula su conflicto, tienen derecho a que esos errores sean corregidos por el máximo tribunal de la República, siendo únicamente ellos los que pueden calificar el agravio y perjuicio que le causa el vicio que afecta a la sentencia dictada con error de derecho.

El citado artículo señala que toda sentencia de un órgano que ejerza jurisdicción debe fundarse en un proceso previo legalmente tramitado, $y$ agrega que corresponde al legislador establecer las garantías de un racional y justo procedimiento. La procedencia del recurso de casación en el fondo es uno de los instrumentos más importantes para dar eficacia a este derecho constitucional.

A propósito de esta materia, debe igualmente recordarse el principio establecido por el artículo $19, \mathrm{~N}^{\circ} 2$, de la Constitución, en cuanto expresa que ni la ley ni autoridad alguna podrán establecer diferencias arbitrarias, lo que debe tenerse en cuenta para la adecuada decisión de la materia sometida al conocimiento de este Tribunal Constitucional. 
c.- Recursos procesales. Son los medios que la ley franquea a las partes para impugnar las resoluciones judiciales...

El establecimiento de recursos es una de las principales garantias que las partes tienen en el desarrollo del proceso... " 18

\section{Jurisprudencia Internacional}

Recientemente, el 2 de julio de 2004, la Corte Interamericana de Derechos Humanos se pronunció en Herrera Ulloa con Costa Rica y lo hizo en términos que fuerzan, ahora con mayor y decisiva razón, a una muy completa transcripción:

"Los Estados tienen la responsabilidad de consagrar normativamente y de asegurar la debida aplicación de los recursos efectivos y las garantias del debido proceso legal ante las autoridades competentes, que amparen a todas las personas bajo su jurisdicción contra actos que violen sus derechos fundamentales o que conlleven a la determinación de los derechos y obligaciones de éstas...

En relación con el proceso penal, es menester señalar que la Corte, al referirse a las garantías judiciales, también conocidas como garantías procesales, ha establecido que para que en un proceso existan verdaderamente dichas garantias, conforme a las disposiciones del artículo $8^{\circ}$ de la Convención, es preciso que se observen todos los requisitos que "sirvan para proteger, asegurar o bacer valer la titularidad o el ejercicio de un derecho", es decir, las "condiciones que deben cumplirse para asegurar la adecuada defensa de aquéllos cuyos derechos u obligaciones están bajo consideración judicial"...

De conformidad con la legislación costarricense, contra una sentencia condenatoria emitida en el proceso penal solamente se puede interponer el recurso de casación. Dicho recurso se encuentra regulado en los artículos $443^{\circ}$ a $451^{\circ}$ del Código Procesal Penal de Costa Rica.

a) Derecho de recurrir del fallo ante un juez o tribunal superior (artículo 8.2.h. de la Convención)

El artículo 8.2.h. de la Convención Americana dispone que durante el proceso, toda persona tiene derecho, en plena igualdad, "de recurrir del fallo ante juez o tribunal superior".

La Corte considera que el derecho de recurrir del fallo es una garantía primordial que se debe respetar en el marco del debido proceso legal, en aras de permitir que una sentencia adversa pueda ser revisada por un juez o tribunal distinto y de superior jerarquía orgánica. El derecho de interponer un recur- 
so contra el fallo debe ser garantizado antes de que la sentencia adquiera calidad de cosa juzgada. Se busca proteger el derecho de defensa otorgando durante el proceso la posibilidad de interponer un recurso para evitar que quede firme una decisión que fue adoptada con vicios y que contiene errores que ocasionarán un perjuicio indebido a los intereses de una persona.

La Corte ha indicado que el derecho de recurrir del fallo, consagrado por la Convención, no se satisface con la mera existencia de un órgano de grado superior al que juzgó y condenó al inculpado, ante el que éste tenga o pueda tener acceso. Para que haya una verdadera revisión de la sentencia, en el sentido requerido por la Convención, es preciso que el tribunal superior reúna las características jurisdiccionales que lo legitiman para conocer del caso concreto. Conviene subrayar que el proceso penal es uno solo a través de sus diversas etapas, incluyendo la tramitación de los recursos ordinarios que se interpongan contra la sentencia...

De acuerdo al objeto y fin de la Convención Americana, cual es la eficaz protección de los derechos humanos, se debe entender que el recurso que contempla el artículo 8.2.h. de dicho tratado debe ser un recurso ordinario eficaz mediante el cual un juez o tribunal superior procure la corrección de decisiones jurisdiccionales contrarias al derecho. Si bien los Estados tienen un margen de apreciación para regular el ejercicio de ese recurso, no pueden establecer restricciones o requisitos que infrinjan la esencia misma del derecho de recurrir del fallo. Al respecto, la Corte ha establecido que "no basta con la existencia formal de los recursos sino que éstos deben ser eficaces", es decir, deben dar resultados o respuestas al fin para el cual fueron concebidos...

El juez o tribunal superior encargado de resolver el recurso interpuesto contra la sentencia penal tiene el deber especial de protección de las garantías judiciales y el debido proceso a todas las partes que intervienen en el proceso penal de conformidad con los principios que lo rigen.

La posibilidad de "recurrir del fallo" debe ser accesible, sin requerir mayores complejidades que tornen ilusorio este derecho.

Independientemente de la denominación que se le dé al recurso existente para recurrir un fallo, lo importante es que dicho recurso garantice un examen integral de la decisión recurrida.

Al respecto, el Comité de Derechos Humanos concluyó [...] que la inexistencia de la posibilidad de que el fallo condenatorio y la pena del autor fueran revisadas integramente, como se desprende de la propia sentencia de casación [...], limitándose dicha revisión a los aspectos formales o legales de la sentencia, no cumple con las garantias que exige el párrafo 5 , artículo 14 del Pacto. Por consiguiente, al autor le fue denegado el derecho a la revisión del 
fallo condenatorio y de la pena, en violación del párrafo 5 del artículo $14 \mathrm{del}$ Pacto.

En el presente caso, los recursos de casación presentados contra la sentencia condenatoria de 12 de noviembre de 1999 no satisficieron el requisito de ser un recurso amplio de manera tal que permitiera que el tribunal superior realizara un análisis o examen comprensivo e integral de todas las cuestiones debatidas y analizadas en el tribunal inferior. Esta situación conlleva a que los recursos de casación interpuestos por los señores Fernán Vargas Rohrmoser y Mauricio Herrera Ulloa, y por el defensor de éste último y apoderado especial del periódico "La Nación", respectivamente (supra párr. 95. w), contra la sentencia condenatoria, no satisficieron los requisitos del artículo $8.2 \mathrm{~h}$. de la Convención Americana en cuanto no permitieron un examen integral sino limitado.

Por todo lo expuesto, la Corte declara que el Estado violó el artículo 8.2.h. de la Convención Americana en relación con los artículos 1.1 y 2 de dicho tratado, en perjuicio del señor Mauricio Herrera Ulloa "19.

\section{Conclusiones}

Los Estados tienen un margen de apreciación para regular, en su legislación interna, el ejercicio del derecho a los recursos. Pero contemplando siempre uno que sea de carácter ordinario y que goce de eficacia, mediante el cual un Tribunal Superior procure la corrección de las decisiones contrarias al Derecho y a los hechos, adoptadas por los Tribunales Inferiores. Sin embargo, al regular el ejercicio de aquel derecho, no pueden establecerse restricciones o requisitos que infrinjan su esencia, pues con ello se estaría lesionando el derecho a un procedimiento racional y justo.

Por ende, el régimen de recursos debe garantizar un examen integral de la decisión recurrida, abriéndose, de esta manera, un ámbito extraordinariamente relevante para el perfeccionamiento del Nuevo Proceso Penal, sin que pueda aducirse que el modelo en actual vigencia resulta incompatible con aquel Proceso, puesto que el mayor respeto y promoción de los derechos fundamentales, como el debido proceso, no reviste tan feble argumentación.

19 Considerandos $145,147,149,157$ - 159, 161 y 163 a 168 de la sentencia pronunciada por la Cone Interamericana de Derechos Humanos el 2 de julio 2004, en el Caso Herrera Ulloa vs. Costa Rica. 
